\title{
Reflexive Conversation: Approach to the Professional Learning of Pre-service Mathematics Teachers
}

\author{
Eddie Aparicio Landa ${ }^{1, *}$, Landy Sosa Moguel ${ }^{1}$, Guadalupe Cabañas-Sánchez ${ }^{2}$, Karla Gómez Osalde ${ }^{1}$ \\ ${ }^{1}$ Faculty of Mathematics, Autonomous University of Yucatan, Mexico \\ ${ }^{2}$ Faculty of Mathematics, Autonomous University of Guerrero, Mexico
}

Received January 28, 2020; Revised April 9, 2020; Accepted April 27, 2020

Copyright $\mathrm{C} 2020$ by authors, all rights reserved. Authors agree that this article remains permanently open access under the terms of the Creative Commons Attribution License 4.0 International License

\begin{abstract}
This study examines how reflexive conversation (RC) conducts pre-service mathematics teachers to collective learning. Although the investigations on the development and learning of teachers have shown that reflection and conversation help to improve their practices and favor learning, the relevance of this study lies in that there still remains the need to find more profound ways on how to achieve it. To this end, this study focuses on the RC. Eleven students in a mathematics teacher education program and their instructor participated in this study; they were observed during two sessions of ninety minutes each, while they thoughtfully discussed the solution for a mathematical task. A qualitative analysis was conducted to understand the learning developed by the participants in the RC context following two principles of conversational analysis: (i) turn taking, and (ii) sequence organization. The principal theoretical reference was the theory of conversation. It was found that RC steers towards collective learning if the topic, object of conversation, is discussed in a free, open and flexible way. The participants transformed their individual knowledge through discussion and negotiation of meanings into a common knowledge such as this: "the concept of generalization in mathematics does not only consist in the establishment of patterns and rules in arithmetic and algebra, it is also a process to form a mathematical concept". Therefore, RC could be considered in the design or redesign of professional teaching education courses.
\end{abstract}

Keywords Reflexive Conversation, Pre-service Mathematics Teachers, Professional Development, Mathematics Education

\section{Introduction}

Dewey [1] considered that the purpose of education should be encouraging reflexive thinking because people do not learn from experiences but by reflecting upon them. By means of reflection on the ideas and experiences, it is possible to build and give meaning to them and to express these meanings in our thoughts, speech and actions [2]. Reflection has the intentional or deliberative nature to produce some type of results and can be of at least three types: anticipated, updated and retrospective. Schön [3] was one of the first people to place these types of reflection in the professional teaching practices and referred to them as: reflection-for-action, reflection-in-action and reflection-on-action. He claimed that a teacher is more capable in his practice as far as he reflects on what he thinks and does. In fact, thinking and doing are considered as complement processes of learning [4].

In the specific field of mathematics education, the previous positions led to the analysis of reflection in relation to the professional development and learning of mathematics teachers. For example, by analyzing the use of portfolios to develop reflective thinking $[5,6]$ by using narratives to develop a professional identity $[7,8]$ or to increase awareness of the complexity of student learning [9]. In general terms, it has been documented that reflection helps to transform the teaching practice when it is incorporated in education teacher programs [10].

Moreover, previous studies [11,14] have documented that the collaborative participation of in-service teachers or pre-service teachers in the reflection of multiple aspects of teaching helps to integrate their knowledge in order to have a wider vision of its complexity and to make explicit their tacit knowledge. In this way, teachers and their colleagues become aware of the principles that guide their practices, the way they teach and how their students learn [15].

However, Opfer and Pedder [16] claim that it is necessary to advance forward in how teachers learn and the conditions that support and promote their learning because the results obtained have not been sufficiently satisfactory $[17,18]$. It is also necessary to widen the research on how to 
favor a significant reflection among teachers [10]

In this sense, some researchers consider that one way to involve teachers in their professional development and learning is through their participation in research communities dealing with teaching and learning processes $[12,19]$; because sharing their reflections in these communities broadens their visions of the complexities of these processes and of themselves as teachers [14,20].

Raelin [21] points out that reflection is mainly interactive so that conversations between colleagues stimulate it and even allow negotiation and development of a shared understanding of the teaching practice and how to commit to it [22]. Therefore, conversation has an important role in teachers' self and collective reflections because they can lead to a better understanding of the mathematical topic, its teaching and learning on the part of the teachers [23].

The literature has recognized the importance of reflection and conversation for the professional development of teachers and mathematics teachers in particular [24-27] [10,28]. However, they have been treated separately most of the time, accounting for one or the other, and assuming reflection as an inherent part of the conversation. It has also been reported several times that collective reflection does not occur as often as it should be expected in professional learning communities [29] and that when teachers show signs of reflection on their practice, they focused on the teaching aspect rather than on learning, including their own [6]. Therefore, more research is needed on how to promote significant reflections among teachers [10].

Research, such as Needham's [30], mentioned five "different forms" in which conversation has been connected with learning and professional growth. However, it is not clear how reflection is present in the conversations, and even when reflection is an essential aspect of the learning of teachers, its efficient development requires scaffolding for its integration into the professional practice [31]. Based on the above, it is thought that reflexive conversation could be the articulating concept that provides an additional insight into the professional development processes of future teachers with emphasis on the conversational.

According to the main idea regarding the theory of conversation, learning is produced through conversations about a topic. These conversations make knowledge explicit and lead to the formation of new shared concepts [32-34].

In consequence, we consider it necessary to study how $\mathrm{RC}$ between pre-service mathematics teachers constitutes a means to promote professional development and learning; we specifically focus on their professional practice because, as mentioned before, conversation is the basis of individual and collective reflection which, in turn, takes form of knowledge and learning for the interlocutors $[32,35]$.

The purpose of this paper is to inform about how reflexive conversation favors the learning of pre-service mathematics teachers, considering that professionals develop their knowledge through a reflexive process of formulation and reformulation of problems [3] and that all professional conversions have the potential to have a more profound professional knowledge [36]. We are particularly interested in the characterization of a $\mathrm{RC}$ space in which the thoughts and actions of the participants are constituted in collective learning. In this sense, we examine how reflexive conversation can lead to a collective learning of pre-service mathematics teachers in the context of a Didactics of Mathematics course.

\section{Theoretical Framework for RC}

For Pask [34] conversation involves a process of negotiation of shared understandings which leads to the emergence of knowledge. Therefore, conversational learning is to have a dialogue between peers who build their understanding through exchanges of their ideas, thoughts and feedback. He proposed a cyclic model of learning (Figure 1) between two participants (teacher and learner) concerning a topic named "the skeleton of a conversation". 


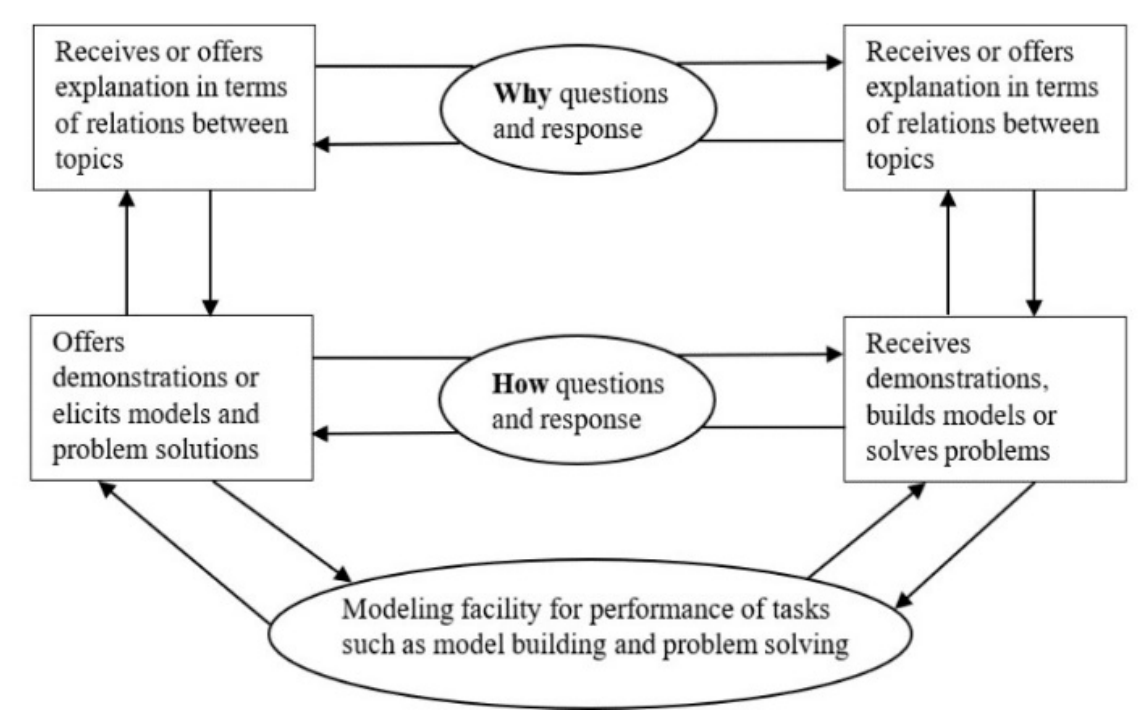

Figure 1. Pask's skeleton of a conversation. Source: Scott (2001, p. 352)

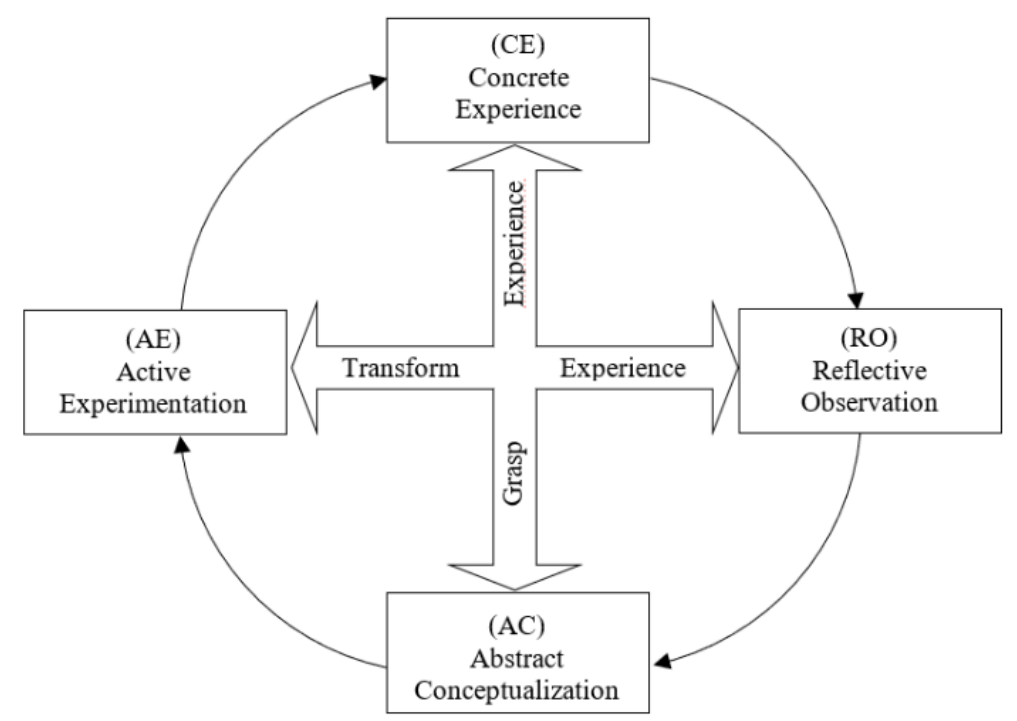

Figure 2. The Experiential Learning Cycle (Kolb \& Kolb, 2017, p. 32)

The horizontal connections in this skeleton represent verbal exchanges that can occur in at least two levels, the how and why, relative to the procedural and conceptual knowledge, respectively. The vertical connections represent causal relationships with feedback, a hierarchy of processes that controls or produces other processes. There is a canonical world in the lower level of this hierarchy in which the teacher may induce or exemplify the topic through non-verbal demonstrations [37].

In the conversation theory of Pask, learning is the result of an interaction between two or more participants that intentionally look for a common understanding, and even when the answers to specific questions of a topic are personal, the meaning is produced by agreements based on the conversation. In other words, understanding is built individually [38], and learning consists of changes in the individual structure of knowledge.

In a similar way to Pask, Kolb and Kolb [4] defined "conversational learning" as a process in which people build new meanings and transform their collective experiences in knowledge through conversations. They proposed an experiential learning cycle composed of four learning modes: Concrete Experience (CE), Reflective Observation (RO), Abstract Conceptualization (AC) and Active Experimentation (AE) (figure 2). CE mode consists in learning from experiencing/feeling; mode RO is related to observing and reflecting on what has been done/experienced in $\mathrm{CE}$ (learning by processing); mode $\mathrm{AC}$ is related to theorizing or generalizing the experience from RO (learning by generalizing), and mode $\mathrm{AE}$ is related with implementing or proving a theory for future experience (learning by doing). The central arrows in Figure 2 indicate the dialectic relationships between these learning modes in the cycle. On the one hand, it shows the relationship (CE - AC) by which the experience is captured; on the other hand, it shows the relationship (RO $-\mathrm{AE}$ ) by which the experience is transformed. 


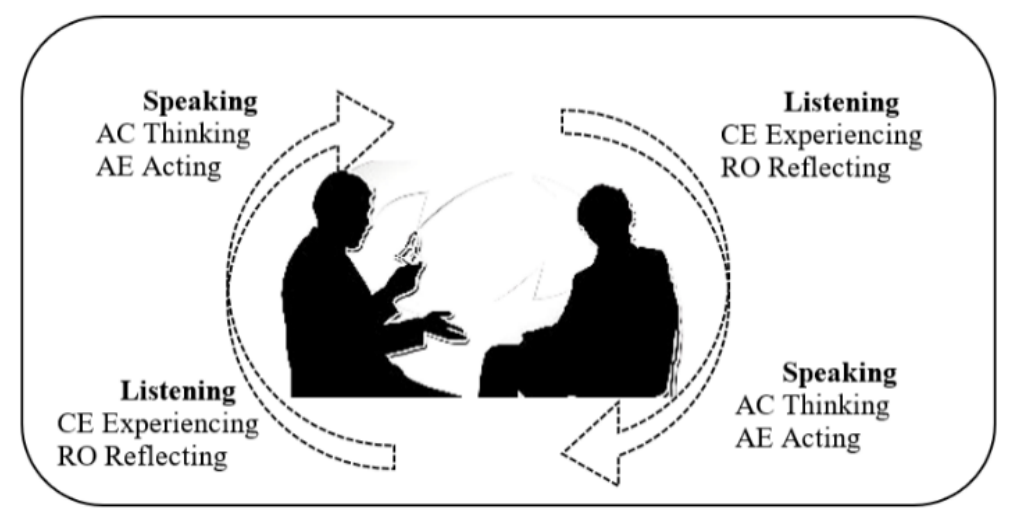

Figure 3. Conversational learning cycle (Kolb \& Kolb, 2017, p.191)

In this way, conversational learning implies a cyclic, dialectic and holistic process of adaptation to the world in which transactions between a person and the environment are given [1]. Baker, Jensen and Kolb [33] claim that the experiential is the principal source of learning and that learning is reinforced as far as people pass through the cycle of experience, reflection, abstraction and action; in this way, they construct meanings from their experiences during conversation. The authors argued that people construct shared meanings through conversations based on their experiences and improve their understanding as they remain open to dialogue.

Figure 3 shows this conversational learning process. It represents that while a person is receiving feedback (CE) and formulating perceptions (RO), the other one is creating intentions based on these perceptions (AC) and acting on them (AE).

In a certain way, the models of Pask, and Kolb and Kolb complement each other. The conversational learning model of Pask consists of dialogical interactions based on the exchange of ideas on a specific topic; learning is produced by means of questioning (questions and answers). On the other hand, the conversational learning model of Kolb and Kolb consists of dialogical interactions based on opposites and contradictions in the topic of discussion to achieve learning. In addition, in the model of Pask, learning is not just a matter of the evolution of schemes as in the Kolb and Kolb's model, but also considers the relationship with the content. Both models identify the role of dialogue to foster learning, either with a chain of questions and answers, or an acceptance of differences, contradictions and conflicts that occur during the discussion leading to the emergence of meanings [39].

Having said this, both models make little reference to reflection as part of conversations, and according to Dewey [40], learning does not come from our experiences but from reflecting upon them. Reflection must be with the mental action of representing actions before the individual and with the process of construction of objects (meaningful things). Therefore, it is necessary to extend the idea of conversation to reflexive conversation with the purpose of deepening and completing understanding about how and who will participate in it and foster professional learning.

In the context of the theoretical frameworks described above, an RC involves more than sharing information or experiences where the participants may or may not agree [37]. It involves speaking and listening reflexively [41], this is, a willingness to engage in a dialogue in which ideas are exchanged and articulated through the negotiation of meanings, the acceptance of questions and the argumentation of ideas that could eventually lead to a new understanding of the topic of conversation.

Therefore, the concept of RC in this study includes the transformation of individual and collective thoughts and actions of the interlocutors associated with a topic of conversation or situation, when they are able to reach higher levels of awareness of the consequences, with the implicit or explicit support of open questioning and interaction of opposites and contradictions.

Consequently, the integration of the models described above is proposed to examine how reflexive conversation is involved in producing professional learning (Fig. 4). 


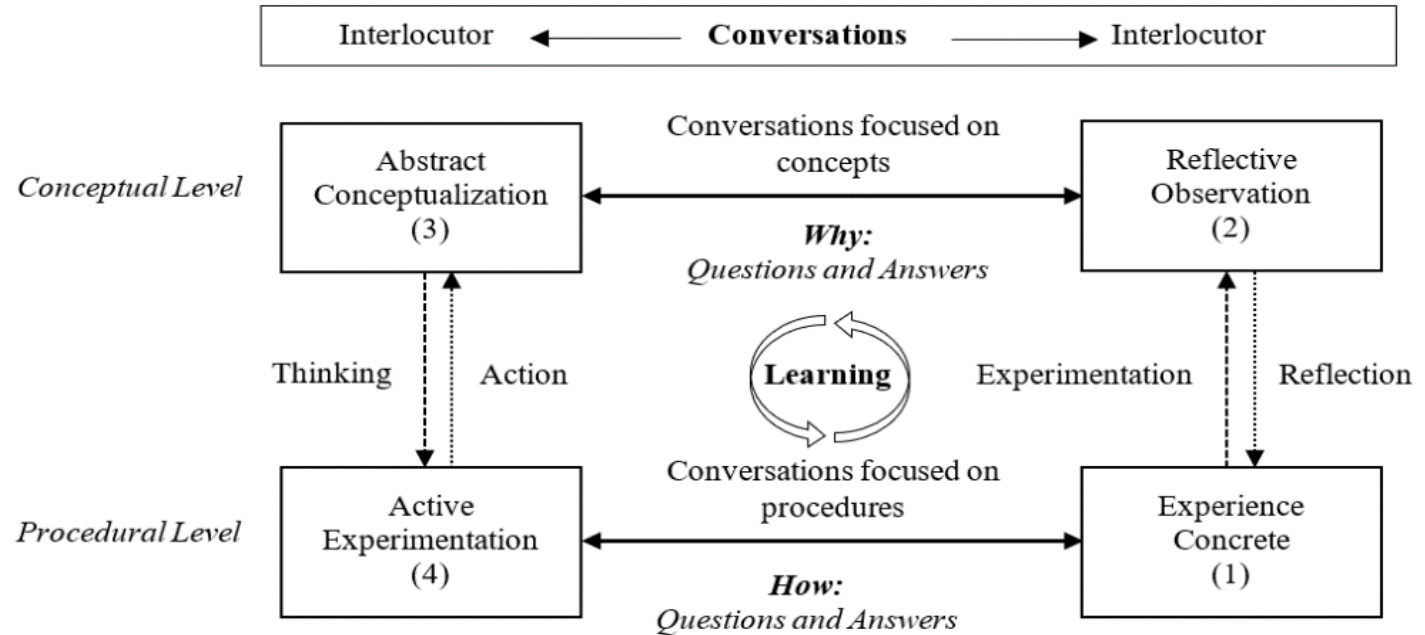

Figure 4. Reflexive conversation and collective learning based on Pask (1976) and Kolb and Kolb (2017)

Learning by perception (how) is in the first level of figure 4; while learning by information processing (why) is in the second level, which is perceived as more demanding in a cognitive sense; however, they complement each other to produce deeper learning. The two conversational levels are connected through causal processes like experimentation, reflection, thinking and action.

\section{Method of Study}

Due to the interest in understanding the learning of future teachers from their conversational interactions in the context of an RC, a qualitative-interpretative methodology [42] was chosen; this methodology considers that knowledge comes from the subject-object interaction in such a way that the interactions, between people and the environment and between thoughts and meanings are the focus of the analysis [43].

\subsection{Context of the Study}

This study was carried out in the context of a Didactics of Mathematics course which is taught in the last semester of a mathematics teacher's education program in a public university in Southeastern Mexico. This program lasts for eight semesters and includes mandatory, elective and free courses related to teaching development in areas like mathematic topics, didactics of mathematics and the use of technology with educational orientation, among others.

The course has duration of 48 hours distributed over 16 weeks, with 2 sessions of 90 minutes of classroom work per week. During this period of time, aspects related with the teaching and learning of mathematical contents in basic and secondary education, such as arithmetic, algebraic, geometric, and statistics contents are addressed with an average of 12 hours per content. The work is essentially participatory, and the teacher plays the role of guide.

\subsection{Instrument for Collecting Information}

Bearing in mind that conversational learning may start by interacting with questions such as the "how" and "why" of a specific topic [34] and that the requirements for solving a problem are factors in a guidance of reflection [1], it was decided to use a mathematics task in an open question mode so it could be the object of discussion and reflection.

The instructor posed the task in the following way: To what extent is it possible to infer that an even number is the result of multiplying two consecutive integers? This task was proposed near the beginning of the course (second week).

\subsection{Participants}

There were eleven participants ( 8 women and 3 men) in this study with an average age of 22 years. The instructor was a member of the research team. She has a doctoral degree in the field of mathematics education and five years of experience in the teacher education program. The criteria for selection of the participants were to be students in the last semester of this program and to be enrolled in a course where they used their previously learned mathematical and didactic knowledge.

\subsection{Data Collection}

We refer to the participants in this study with the codes W1, W2, W3... W8, for women, and M1, M2, M3, for men, to maintain their anonymity. The code for the teacher is $\mathrm{T}$.

The participants were organized into four teams of two people and one of three to solve the task. They were then asked to share their answers with the entire group. Every team chose one member to present their results and, if 
necessary, other members of the team make precisions or clarify the exposition. The teams were organized in the following way: (W1, W2), (W3, M1), (W4, W5), (M2, M3), (W6, W7, W8).

Two sessions in total were carried out, each one lasted 90 minutes. The registered conversations focused on the posed task. The information was collected through nonparticipant observation; the conversational interactions between the instructor and the group of students were audio and videotaped. All records were transcribed for their analysis.

\subsection{Analysis of Data}

For the first part of the qualitative analysis, the conversations were organized based on two principles of conversation analysis [44]: (i) turn taking, and (ii) sequence organization. The turns taking are determined by the moment in which the interlocutors change the speaker-listener roles, allowing them to detect thematic episodes, which form organizational sequences (coherent sentence sequences). Thus, in order to understand learning in a conversational interaction, the conversations were divided into propositions [45], understood as units of knowledge, that is, sentences with one single predicate [44].

Subsequently, based on the scheme of Figure 4, the organized data was analyzed in two ways. The first way consisted in the identification of propositions related to knowing how and knowing what. In doing so, a review was conducted of the conversation episodes associated with information exchanges on how the future teachers managed to solve the task and their justifications for their answers (why), focusing on the type of reflection used in their actions. The second way consisted in the identification of the modifications of the thoughts of the future teachers as a result of their reflections and negotiation of meanings.

To identify and describe reflections on a procedural level, it is useful to consider them as characterized by discussions focused in the construction or use of procedures connected with the solution of the task; while for reflections on a conceptual level, it is considered that thoughts are characterized by focusing on the use of conceptual ideas or theories.

\section{Results}

\subsection{Actions and Reflections in Conversations}

This section shows how actions and reflections during conversation on the procedural level indicated in figure 4 are characterized by discussions focused on the mathematical content of the task and its specificity; namely, to determine to what extent it is possible to infer if the product of two consecutive integers is an even number.

Before the conversation and group discussion, two teams wrote their answers to the task on the board. Image 1 shows the written response of team (W1, W2) and image 2, the response of team (W3, M1).

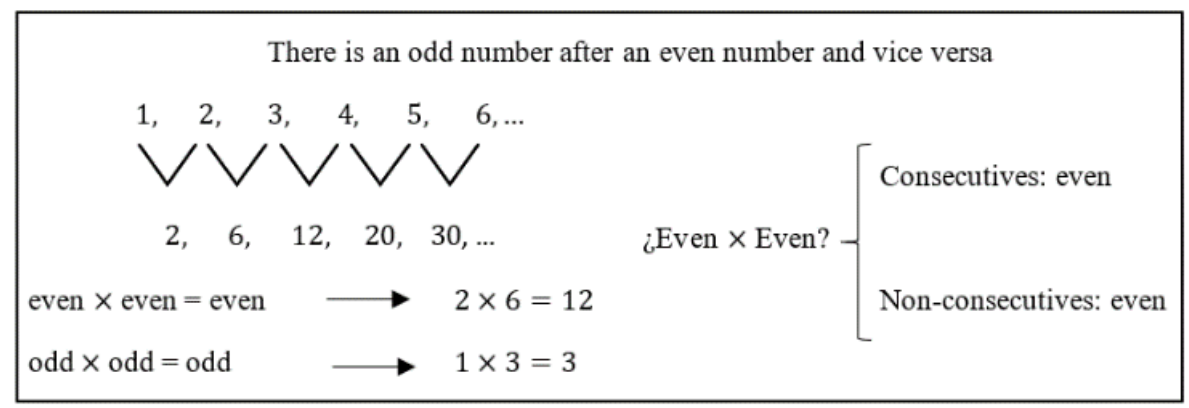

Image 1. Written response of the team (W1, W2) on the board

One of two consecutive numbers is necessarily odd and the other is even

$$
a, a+1, a+2, \cdots
$$

We have the product of an even number and an odd number

- If $p$ is even $\rightarrow p=2(r), r$ being any number

- If $q$ is odd $\rightarrow p \cdot q=2(r) q=2(r q)$ This product is even.

Then, the product of two consecutive numbers is even, because one of them is a multiple of two. Then, its product should also be a multiple of 2 .

Image 2. Written response of team (W3, M1) on the board 
The initial conversations of the pre-service teachers focused on discussions that recognized or verified if the result of the multiplication of two consecutive integers is an even number. The level of the content of the conversation was procedural because it was based on the use of multiplications of specific cases of even and odd numbers. This was observed in the following excerpts of the conversation:

01: (W1, W2): (...), What happens if we multiply two even numbers? $2 \times 6=12$, but they are not consecutive numbers.

An odd number with an odd number also gives us an odd number.

02: (M2, M3): (...), this is for cases, as he mentioned. Arithmetic is about a student indicating, for example, that $2 \times 6=12$, thinking cases [points to image 1]. In contrast, (...), algebraic thinking is about taking two consecutive numbers, but bigger numbers, and asking what happens; and, therefore, generalizing what happens in this case (...)

03: (W3, M1): (...), I would consider generalization as a proper part of the algebraic thinking; however, identification of patterns, the relationship between quantities, is part of arithmetic. In this case, there is a certain relationship between the quantities that are increasing: 2 leads to 4 , and then to 6 , and there are always two units, (...) one could conclude that the multiplication of two consecutive numbers is even, generalization!

04: (W4, W5): At the beginning, we thought that there could be no generalization in arithmetic (...) However, after reflecting on what we understand as generalization, for example here, if the result of multiplying two consecutive numbers is an even number, then it is a generalization (...) We realized (...) that there could be generalizations in arithmetic and algebra (...) We started thinking about the specificities of each area (...), we reconsidered and thought that there could be generalizations in arithmetic. And we said that in the sequence [images 1 and 3], it is satisfied from 2 to 6,4 is missing and it can be generalized as being multiples of two, as said before.

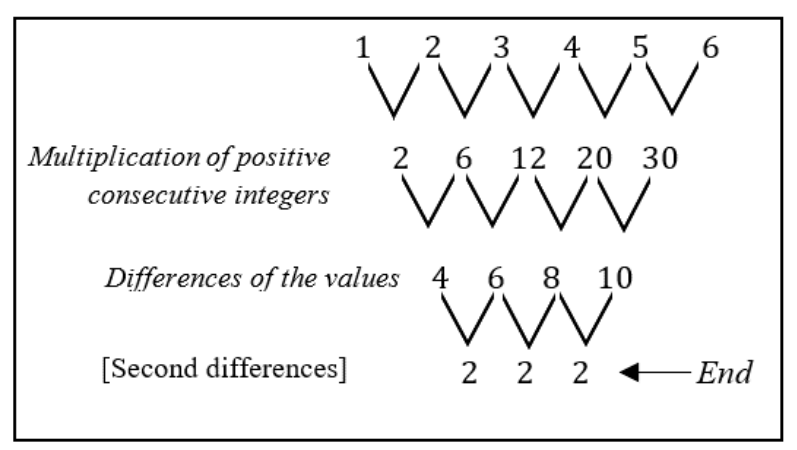

Image 3. Multiplication of consecutive integers and their differences, written by $\mathrm{W} 4$ on the board

05: (W3, M1): How are the results of two consecutive numbers? 2, 6, 12, 20 and 30 . There is a multiplicative relationship: $2 \times 1,2 \times 3,2 \times 4,2 \times 5,2 \times 15$, I would see that, but I think it would take me away from the point.

06: (W1, W2): We say that a number is one way to generalize in arithmetic. We saw the proof proposed by our classmates later and we started to think that literals participate in some way; we wondered if we were talking about algebra.

We think that on what (W4, W5) are talking about, it would be a construction or searching for the behavior of a sequence.

07: (W1, W2): There [image 4], it would satisfy that the product of two consecutive integers is an even number, and we can see that they have the number two in common (...)

08: (M2, M3): How could you come to a representation? We mean, to something more general. We think it is interesting.

09: (W3, M1): (...) We are seeing it now, what is the meaning of the position in this context? We think it is a way to place the previous rectangle in the actual one [image 4].

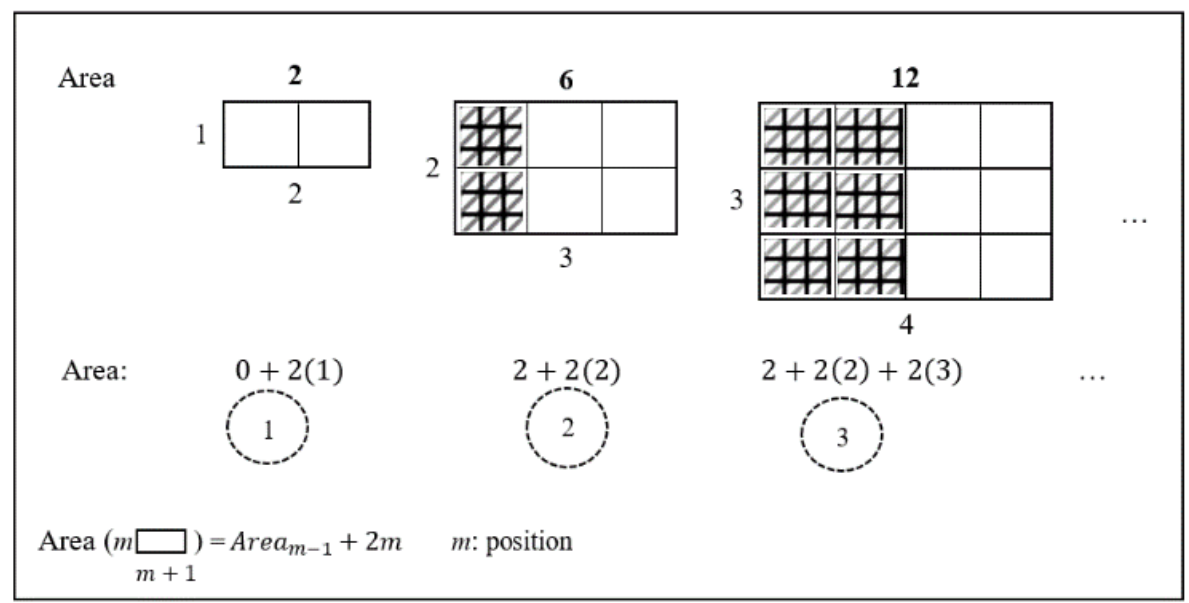

Image 4. Process followed by M1 to interpret $2 k$ as a generalization 
It was identified that the participants tried to generalize the result when they questioned what could happen by multiplying two consecutive numbers or big numbers 02 . This means that they were asking for the general conditions in which the product of two numbers is even and supported their arguments in the use of geometrical and literal representations (Image 4). For example (Image 3), M1 looks for a pattern on how the product of the multiplication of two consecutive numbers is increasing through the estimation of the recursive differences (based on the answer of W4) in 03. He gave a geometrical representation that illustrated the pattern followed by the numbers $2,6,12 \ldots$ in order to show evidence of what he said and persuade his fellow participants. These conversations lead the participants to a reflection, 04 and 06 , to generalization in arithmetic and algebra. Therefore, the actions and conversations extend beyond the specificities of the task and lead to reflections on the concept of generalization in mathematics.

Three types of reflections were identified in the conversations:

Anticipated reflections: They were characterized for referring to future actions. These actions were related to the teaching of the arithmetic content of the task. The next lines of the dialogue show some of these reflections.

10: (M2, M3): We wonder if this is a trivial question for an elementary school student, yes or no and why? And then, is this trivial for a high school or a university student?

For example, this [image 2], can an elementary school student do it? We think that this is an answer of a university student.

11: (W3, M1): We think that if an elementary school student knows how to generalize, then it could be said that he could also make interpretations.

12: (M2, M3): This could be considered as an initial point for teaching even numbers.

Updated reflections: They are expressed in present indicative. They were made in connection with the mathematical content of the task, as shown in the excerpts 13 through 17, or with their teaching (excerpts 18 and 19).

13: (M2, M3): We think that these types of answers depend on previous knowledge and actual tools to establish connections. Because, similar to the answer of (image 2), one could consider an integer $n$ and $n+1$, sorry, $n$ an even number, and $n+1$ an odd number, then by multiplying them, we get $n^{2}+n$ and conclude that it is even. Is it easy? What does it say to me? Or, what is missing? Is there another proof to conclude it is even? We could say, you know, is it easy?

14: (W3, M1): We still think there is a relationship between the numbers. We are trying to see a relationship. How are the results of two consecutive numbers: $2,6,12$, 20 and 30 ? There is a multiplicative relationship $2 \times$ $1,2 \times 3,2 \times 4,2 \times 5,2 \times 15$, We could see that, but we think it would take me away from the point.

15: (W1, W2): We were discussing and thinking about generalization in arithmetic and all what was mentioned above.

We say that a number is one way to generalize in arithmetic.

16: (W6, W7, W8): We was thinking about what was mentioned on the use of the variable.

17: (W3, M1): What was mentioned in line 09.

18: (M2, M3): We were also thinking that it could represent a linear behavior of a function in Calculus.

19: (W1, W2): We think that what (W4, W5) mentioned would be the construction (...) of a sequence.

Retrospective Reflections: They are expressed in past time. Most of them were made in connection with teaching the arithmetic content of the task. The next lines show some of the reflections.

20: (W3, M1): It could be the transition between arithmetic and algebraic thinking. We don't know, if recognizing an algebraic or arithmetic structure implies this transition. In elementary or secondary school, we detail this data, don't we? This is, an even number multiplied by an even number is even; or an odd number multiplied by an odd number, is odd; but there is a doubt left if this is always satisfied. For example, with bigger numbers (...).

21: (W4, W5): What was mentioned in line 04.

22: (W1, W2): What was mentioned in line 06.

23: (W3, M1): Then the solution proposed is an arithmetic structure, isn't it?

We made a reference to something like this, a transition to the algebraic thinking.

\subsection{Thinking in Conversations}

This section shows how actions and thinking, corresponding to the conceptual level indicated in Figure 4 , refer to discussions focused on knowledge and mathematical conceptualizations, specifically the ones related to arithmetic and algebraic generalization. The development of thinking was observed when the students went beyond the particularities of the task and focused on wider aspects, such as the meanings of generalization, its teaching and learning on different educational levels. Furthermore, the participants managed to identify their own thoughts related to the thoughts of others, being able to withdraw their statements, improve them, or even complement in a mathematical or didactical way.

The identified thoughts were organized into two types:

Divergent thinking: It is characterized by generating ideas in several directions searching for "the best" solution to a problem. The next lines show examples of this type of thinking:

24: (W3, W1): We considered what would happen if we multiply two even numbers.

For example, $2 \times 6=12$, but they are not consecutive.

An odd number with another odd number also results in an odd number.

We considered what would happen if we multiply two 
consecutive numbers, one even and one odd.

25: (W3, M1): What was mentioned in line 03.

26: (W3, M1): What was mentioned in line 14.

27: (W4, W5): We propose thinking the even number named $2 \mathrm{k}$ as the measure of the area of a rectangle.

For example, the rectangle with base 2 and height 1 , this is of area 2, and so on. It would be like generalizing the pattern.

Convergent thinking: It is characterized by looking for "the correct answer" to a problem in a logical way; for example, detecting common patterns or regularities that could lead to the abstraction of a general concept. The next excerpts are examples of this type of thinking:

28: (M2, M3): What was mentioned in Line 13.

29: (M2, M3): We think it different. We consider that algebraic thinking requires the development of a thinking approach to establish relationships between variables and constants, so generalization would not be exclusive of algebra. In fact, it is possible to generalize in calculus and geometry. Let's say that generalization does not only appear in algebra, it appears in all branches of mathematics.

30: (W1, W2): We say that a number is one way to generalize in arithmetic.

31: (W6, W7, W8): (...), the use of literals does not imply that it is algebra.

32: (W3, M1): We think there is some difference between arithmetic and algebraic thinking; arithmetic thinking involves a process of generalization.

33: (W6, W7, W8): It depends on the interpretation we make for $2 k$, if we think of $k$ as a general number.

34: (W3, M1): We can share our idea of what (W4, W5) they said [shares image 4]

\subsection{Reflexive Conversations}

Two reflexive conversation (RC) moments concerning the posed tasks were identified in the context of the recorded conversations. The first moment relates to the mathematical and didactical content in the task. This is exemplified with the following dialogues.

35: (M2, M3): For example, this [the answer of (W3, M1)] ... can an elementary school student do it? (...), it depends on the knowledge and educational level (...)

36: (W3, M1): When we are in this transition of thinking, it is possible to specify and conclude a result.

It was observed that the participants were not only becoming aware of the consequences of their actions and thoughts in this task, they also related them with the cognitive demands in teaching and learning arithmetic and algebra by educational level. For example, the ability to transition between arithmetic and algebraic thinking (see also lines 10, 13 y 20 .

The second moment of RC involves questions and contradictions around their thoughts and actions in the task; these led to a "natural evolution" of the conversation interactions focused on the negotiation of ideas and meanings, specifically in the concept of generalization in mathematics. In this regard, the following dialogical excerpts are shown:

37: (W4, W5): (...), mathematics is about patterns, relationships and generalizations, (..) then (..) generalization occurs in all areas of mathematics (...)

38: (W4, W5): (...) we considered that there could be no generalization in arithmetic, that was our idea, (...), but after reflecting on what we understand as generalization (...) we realize and conclude that it is possible to make generalizations in arithmetic and algebra, but in a different way, (...) we now retract and (...) yes, there can be generalization (...)

39: (W3, M1): We are still (...); however, there is a transition to algebra.

40: (W1, W2): (...) the number is one way to generalize in arithmetic.

41: (W6, W7, W8): the use of literals does not imply that it is algebra.

42: (W6, W7, W8): (...) It can be arithmetic or algebra, it depends on the interpretation we make for the expression $2 k$.

43: (W1, W2): There, (...) The product of two consecutive integers is an even number which is satisfied (...)

44: (M2, M3): Yes, this could be considered as an initial point for teaching even numbers.

45: (W3, M1): We are seeing it now, what is the meaning of the position in this context? We think it is a way to place the previous rectangle in the actual one.

Reflexive conversations led to common understanding of the collective; they began by sharing their approaches, processes, ideas and meanings. At the beginning, the RC was focused on the specificity of the task and their respective answers. Later, there were questionings on the procedural level of those assertions. However, these discussions "evolved naturally" from opposites and contradictions until they reached a conceptual level. This passage between reflexive conversations from procedural to conceptual, together with the emergence of shared meanings, provides evidence of the learning of this group of pre-service teachers. The next section discusses the way in which the reflexive conversation contributed to the collective learning.

\subsection{Learning and Reflexive Conversations}

Conversational learning is a process of the construction of (new) meanings and understanding of a topic in a shared way, which constitutes knowledge [4, 34]. Therefore, learning in the framework of an $\mathrm{RC}$ is the transformation of individual knowledge or of its structure as a result of the negotiation of meanings from which interlocutors acquire higher level of awareness about the consequences of their thoughts and actions relative to the 
topic of conversation supported by questionings, and interaction with opposites and contradictions.

An example of learning in $\mathrm{RC}$ is the fact that the participants transformed their individual knowledge through discussion and negotiation of meanings into a common knowledge such as this: "the concept of generalization in mathematics does not only consist in the establishment of patterns and rules in arithmetic and algebra (including other areas of mathematics), it is also a process to form a mathematical concept; in this case, the concept of even number". The excerpts 02, 03, 04, 06 and 37 give evidence of this transformation.

In this sense, conversational learning is the result of reflections and changes in the way of thinking of the participants; it started with a guided discussion by questioning the understanding between two teams that were at different conversational levels; for example, the discussion of team (W1, W2) was at a procedural level, while team (W3, M1) was at a conceptual level.

Contradiction in thoughts, negotiation of ideas or the fact of living a dialectic to understand the experience "Grasp experience" [4], fostered the movement of the approaches and the passage of conversation towards the transformation of the experience "transform experience"; for example, team (W1, W2) moved to a conceptual level, while (W3, M1) moved to a procedural level.

The conversational learning described was enhanced by a dialogue which combines questions and answers; the contradictions appeared, and the differences were accepted. According to Bakhtin [39], dialogue aligns discussion and meanings. This also agrees with Simoncini, Lasen and Rocco [46] who report that a guided dialogue enhances the future teachers to obtain better perspectives of their teaching practices, including their ways of thinking and doing.

\section{Discussion}

This study characterized the notion of RC and described its relationship with the emergence of collective learning among pre-service mathematics teachers in the context of a didactics of mathematics course.

Some investigations show that, even when it is possible to conduce some conversations between teachers to the reflection on their practice, it is still necessary to specify the type of tools needed to achieve this, such as coaching and the use of structured questions $[47,48]$. In this study, the reflexive conversation allowed the emergence of professional learning opportunities in future teachers by encouraging an exchange and articulation of ideas. RC was based on the questioning of mathematical knowledge and its use in the resolution of a task, the argumentation of the procedures and concepts used, as well as in the negotiation of meanings associated with them. Thus, future teachers generated common understandings about the type of cognitive demands in learning arithmetic and algebraic contents, and they specifically reached a consensus on the meaning of mathematical generalization. In other words, RC provided opportunities to develop knowledge of mathematical and pedagogical content among participants.

Figure 5 shows how RC enabled the passage between the modes of learning in figure 4; the issues that favored the transit between the two levels of conversation: questioning, contradiction, negotiation of meanings and generation of agreements.

\begin{tabular}{|c|c|c|c|c|c|c|c|}
\hline \multicolumn{3}{|c|}{$\begin{array}{l}\text { Moment 1. RC on the didactic and } \\
\text { mathematical content of the task }\end{array}$} & \multirow{3}{*}{ 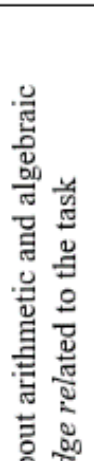 } & \multirow{4}{*}{ 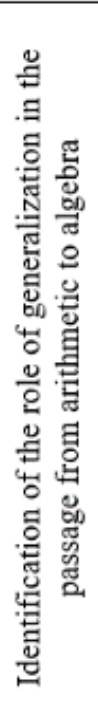 } & \multirow{4}{*}{ 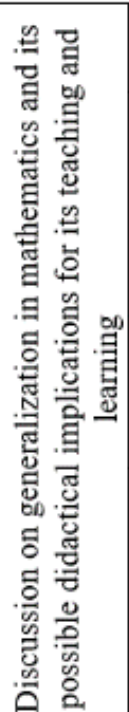 } & \multicolumn{2}{|c|}{$\begin{array}{l}\text { Moment 2. RC on the pertinence of } \\
\text { the actions in the task. }\end{array}$} \\
\hline (W1, W2) & $\mathrm{CE}$ & $\begin{array}{l}\text { Response to the } \\
\text { task by means of } \\
\text { the analysis of } \\
\text { cases. }\end{array}$ & & & & RO & $\begin{array}{l}\text { Even number is a generalization in } \\
\text { arithmetic. There is generalization } \\
\text { in all areas of mathematics. }\end{array}$ \\
\hline \multicolumn{3}{|c|}{$\begin{array}{l}\text { Dialectic to } \\
\text { understand the } \\
\text { experience }\end{array}$} & & & & & $\begin{array}{l}\text { Dialectic to } \\
\text { transform } \\
\text { experience }\end{array}$ \\
\hline (W3, M1) & $\mathrm{AC}$ & $\begin{array}{l}\text { Response to the } \\
\text { task by using the } \\
\text { structures of even } \\
\text { numbers } 2 k \text {. }\end{array}$ & 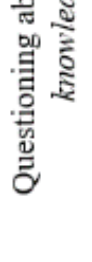 & & & $\mathrm{AE}$ & $\begin{array}{l}\text { Generalization is also a process. } \\
\text { This implies its development as a } \\
\text { mathematical ability. }\end{array}$ \\
\hline
\end{tabular}

Figure 5. RC and transition between ways of learning 
Reflection is a key aspect in training teachers and their learning; however, researchers report that its efficient development requires scaffolding for its integration with the professional practice [31]. This investigation suggests that the emergence of spaces for reflexive conversation characterized by a free, open and genuine discussion among pre-service mathematics teachers does not only enhance reflection processes, but also generates collective learning associated with their future professional practice.

The three types of reflections made by the participants, transformation of their thoughts and actions, and the type of learning generated associated with the proposed task, show that the RC supported the discussion and reflection on their future teaching practice, the learning of the students and the mathematical knowledge. Therefore, the $\mathrm{RC}$ created learning opportunities associated with their mathematical knowledge for teaching. This is in line with the studies associated with the role of conversation in professional learning communities [26, 49].

Results support the idea to continue the research on how to promote reflexive conversation among pre-service teachers and their instructors, because in a short period of time, the pre-service teachers increased their knowledge about the meaning of generalization in mathematics and its possible didactical implications for its teaching and learning. This could enhance the development of a shared vision of the future teaching practice and how to become involved in it [22].

On the other hand, these results are consistent with the studies of Demissie [50], Jaworski [19], Chamoso, Cáceres and Azcárate [6] that suggest that the participation in collective inquiry processes fosters reflexive thinking among pairs. As shown in this research, questioning the mathematical knowledge in the posed task enabled the emergence of several types of reflections and the modification of ways of thinking.

\section{Conclusions}

The integration of the theoretical approaches of Pask [34] and Kolb and Kolb [4] about conversation relative to the modes and learning styles allowed us to have more elements to examine and describe the role of the $\mathrm{RC}$ in the production of collective learning in the context of a professional teaching program. On one hand, the relationships between reflection, conversation and learning, proposed in figure 4, are clarified; on the other hand, it can be seen that questioning, contradiction, negotiation of meanings and generation of agreements are central aspects to conduct a dialogue that leads to collective learning in the context of professional training.

It is considered that $\mathrm{RC}$ can be a means to promote the transition between procedural and conceptual learning in mathematics courses because learning was not just the result of both types of understanding, but it also comes from the conversation. They slowly become aware of their knowledge and future professional practice because of their willingness to discuss in an open and flexible way.

Although the visual resources, such as diagrams and figures on the board, were not part of this study, it can be said that these resources were important to support the interactional conversations, represent ideas and share understanding through specific examples. Especially, they helped in expanding and refining understanding among the participants, complementing their efforts to support or deny their statements in relation with the task.

Finally, we consider it necessary to deepen our understanding of how to involve RC as part of the mathematics teaching programs to make it useful for the development of professional learning in a collective way, as in this study, and to generate anticipated reflections related to the future teaching practice that goes beyond concepts and proper contents of the programs of the course.

\section{REFERENCES}

[1] J. Dewey. Education and Experience. New York, NY: Horace Liveright, 1938.

[2] D. Kolb. Experiential Learning: Experience as the Source of Learning and Development. Englewood Cliffs, NJ: Prentice Hall, 1984.

[3] D. Schön. The reflective practitioner: How professionals think in action. London: Temple Smith, 1983.

[4] A. Kolb \& D. Kolb. The Experiential Educator. Principles and Practices of Experiential Learning. Kaunakakai, Hawaii: EBLS Press, 2017.

[5] J. M. Chamoso \& M.J. Cáceres. Analysis of the reflections of student-teachers of mathematics when working with learning portfolios in Spanish university classrooms. Teaching and Teacher Education, 25(1), 198 - 206, 2009. https://doi.org/10.1016/j.tate.2008.09.007

[6] J. M. Chamoso, M.J. Cáceres, \& P. Azcárate. Reflection on the teaching-learning process in the initial training of teachers. Characterization of the issues on which pre-service mathematics teachers reflect. Teaching and Teacher Education, 28(2), 154 - 164, 2012 https://doi.org/ 10.1016/j.tate.2011.08.003

[7] R. Bjuland, M.L. Cestari, \& H.E. Borgersen. Professional mathematics teacher identity: Analysis of reflective narratives from discourses and activities. Journal of Mathematics Teacher Education, 15(5), 405 - 424, 2012. https://doi.org/10.1007/s10857-012-9216-1

[8] A. Graham, \& R. Phelps. Being a teacher: Developing teacher identity and enhancing practice through metacognitive and reflective learning processes. Australian Journal of Teacher Education, 27(2), 11 - 24, $2003 \mathrm{http}: / / \mathrm{d}$ x.doi.org/10.14221/ajte.2002v27n2.2

[9] T. Lange \& T. Meaney. Professional development 
facilitators: reflecting on our practice. In Wilkinson, J., Bristol, K. and Ponte, P. (Eds.). Professional Development. Education for all as praxis (pp. 81 - 99). New York: Routledge, 2017.

[10] L.L. Saylor \& C.C. Johnson. The Role of Reflection in Elementary Mathematics and Science Teachers' Training and Development: A Meta Synthesis. School Science and Mathematics, 114(1), 30 - 39, 2014.

[11] E.A. Davis. Characterizing productive reflection among preservice elementary teachers: seeing what matters. Teaching and Teacher Education, 22, 281 - 301, 2006.

[12] B. Jaworski. Theory and practice in mathematics teaching development: Critical inquiry as a mode of learning in teaching. Journal of Mathematics Teacher Education, 9, $187-211,2006$

[13] S. Llinares \& K. Krainer. Mathematics (Student) teachers and Teachers Educators as learners. In A. Gutiérrez \& P. Boero (eds.) Handbook of research on the Psychology of Mathematics Education. Past, present and future. UK: Sense publishers, 2006.

[14] D. Potari, H. Sakonidis, R. Chatzigoula \& A. Manaridis. Teachers' and researchers' collaboration in analysing mathematics teaching: A context for professional reflection and development. Journal of Mathematics Teacher Education, 13(6), 473 - 485, 2010. https://doi.org/10.1007/ s10857-010-9161-9

[15] S. Katz, L.M. Earl \& S.B. Jaafar (Eds.) Building and connecting learning communities: The power of networks for school improvement. California: Corwin Press, 2009.

[16] V.D. Opfer \& D. Pedder. Conceptualizing teacher professional learning. Review of educational research, 81(3), 376 - 407, 2011. https://doi.org/10.3102/003465431 1413609

[17] M. Artigue. Problemas y desafíos en educación matemática: ¿Qué nos ofrece hoy la didáctica de la matemática para afrontarlos? Educación Matemática, 16(3), 5 - 28, 2004.

[18] N. Hopwood. Professional practice and learning: times, spaces, bodies, things. Dordrecht: Springer, 2016.

[19] B. Jaworski. Mathematics teacher educator learning and development. In Jaworski, B. and Wood, T. (Eds.). The International Handbook of Mathematics Teacher Education, Volume 4: The Mathematics Teacher Educator as a Developing Professional. Rotterdam: Sense Publishers, 2008.

[20] G.M. Ditchburn. Remembering Reflection in Pre-Service Teachers' Professional Experience. Australian Journal of Teacher Education, 40(2), 94 - 111, 2015.http://dx.doi.org /10.14221/ajte.2015v40n2.7

[21] J.A. Raelin. Toward an epistemology of practice. Academy of Management Learning \& Education, 6(4), 495 - 519, 2007.

[22] A. Preciado Babb, M. Metz \& C. Marcotte. Awareness as an enactivist framework for the learning of teachers, mentors and institutions. ZDM Mathematics Education, 47, 257 268,2015

[23] O. Zaslavsky \& R. Leikin. Professional development of mathematics teacher educators: Growth through practice.
Journal of mathematics teacher education, 7(1), 5 - 32, 2004. https://doi.org/10.1023/B:JMTE.0000009971.13834

[24] A. Arcavi. Promoviendo conversaciones entre docentes acerca de clases filmadas de Matemáticas, Cuadernos de Investigación y Formación en Educación Matemática, 11(15), 385 - 396, 2016.

[25] A. Eriksson. Pre-service teachers' questions about the profesión during mentoring group conversations. European Journal of Teacher Education, 40(1), 76 - 90, 2017. DOI: 10.1080/02619768.2016.1251901.

[26] S. Hairon. Facilitation for professional learning community conversations in Singapore. Asia Pacific Journal of Education, 36(2), 285 - 300, 2016. https://doi.org/10.1080/ 02188791.2016 .1148855 .

[27] K. Rasmussen. Lesson study in prospective mathematics teacher education: didactic and paradidactic technology in the post-lesson reflection. Journal of Mathematics Teacher Education, 19(4), 301 - 324. 2016. https://doi.org/10.1007/ s10857-015-9299-6.

[28] A. Toom, J. Husu \& S. Patrikainen. Student teachers' patterns of reflection in the context of teaching practice. European Journal of Teacher Education, 38(3), 320 - 340, 2015. http://dx.doi.org/10.1080/02619768.2014.943731

[29] C.R. Smith. Continuous professional learning community of mathematics teachers in the western cape: developing a professional learning community through a school-university partnership. Unpublished doctoral dissertation, University of the Western Cape, Bellville, South Africa.

[30] K. Needham. Professional Conversations through a Coaching Lens. East Melbourne, VIC: Centre for Strategic Education. 2016.

[31] P. Roberts. Reflection: A Renewed and Practical Focus for an Existing Problem in Teacher Education. Australian Journal of Teacher Education, 41(7), 19 - 35, 2016. http:// dx.doi.org/10.14221/ajte.2016v41n7.2

[32] M.S. Archer. Structure, agency, and the internal conversation. Cambridge: Cambridge University Press, 2003.

[33] A. Baker, P. Jensen \& D. Kolb. Conversation as Experiential Learning, Management Learning, 36(4), 411 - 427, 2005. https://doi.org/10.1177/1350507605058130

[34] G. Pask. Conversation theory. Applications in education and epistemology. Ney York: Elsevier Scientific Publishing Company, 1976.

[35] L.S. Vygotsky. Thought and language (A. Kozulin, trans.). Cambridge, MA: MIT Press, 1986.

[36] H. Timperley. Professional Conversations and Improvement-Focused Feedback: A Review of the Research Literature and the Impact on Practice and Student Outcomes. Melbourne: Australian Institute of Teaching and School Leadership, AITSL, 2015.

[37] B. Scott. Gordon Pask's conversation theory: A domain independent constructivist model of human knowing. Foundations of Science, 6(4), 343 - 360, 2001

[38] R. Glanville. Conversation and design. In R. Luppicini (Ed.), 
Handbook of conversation design for instructional applications (Chapter V, pp. 59 - 79). Hershey, PA: IGI Global, 2008.

[39] M. M. Bakhtin. Speech genres and other late essays. Austin, Texas: University of Texas Press, 1986.

[40] J. Dewey. How we think. New York: Dover Publications, 1933.

[41] D. Shön. Designing as reflective conversation with the materials of a design situation. Research in Engineering Design, 3(3), 131-147. 1992.

[42] J. Corbin \& A. Straus. Basics of qualitative research. (3rd. ed.). Los Angeles: Sage.

[43] J. Kilpatrick. Change and stability in research in mathematics education. Zentralblatt für Didaktik der Mathematik, 5, 202 - 204.1988.

[44] H. Mazeland. Conversation Analysis. Encyclopedia of language and linguistics, 3, $153-163.2006$.

[45] JP. Gee. An introduction to discourse analysis: theory and method. New York, NY: Routledge, 2011.

[46] K. M. Simoncini, M. Lasen \& S. Rocco. Professional dialogue, reflective practice and teacher research: Engaging early childhood pre-service teachers in collegial dialogue about curriculum innovation. Australian Journal of Teacher Education, 39(1), 27 - 44, 2014.http://dx.doi.org/10.14221 /ajte.2014v39n1.3

[47] D. Huinker \& J. Freckman. Focusing Conversations to Promote Teacher Thinking. Teaching Children Mathematics, 10(7), 352 - 357. 2004.

[48] M. Alice, R. Heaton \& M. Williams. Translating Professional Development for Teachers into Professional Development for Instructional Leaders. Mathematics teacher educator, 6(1), 27 - 39. 2017.http://dx.doi.org/10.5 951/mathteaceduc.6.1.0027

[49] M. Chauraya \& K. Brodie. Learning in professional learning communities: Shifts in mathematics teachers' practices. African Journal of Research in Mathematics, Science and Technology Education, 21(3), 223 - 233. 2017. https://doi. org/ 10.1080/0035919X.2017.1350531

[50] F. Demissie. Promoting Student Teachers' Reflective Thinking through a Philosophical Community of Enquiry Approach. Australian Journal of Teacher Education, 40(12), 1 - 13, 2015. http://dx.doi.org/10.14221/ajte.2015v40n12.1 